BIOMEDICA

Vol. 3 No. 1 y $2-1983$

\title{
VIABILIDAD DEL M. TUBERCULOSIS EXPUESTO AL FOSFATO TRISODICO EN MEDIO DE OGAWA-KUDOH A TEMPERATURA AMBIENTE
}

\author{
EDUARDO ESPER C., * LUIS CARLOS OROZCO V. **
}

\begin{abstract}
Se practicó un estudio en donde se demostró que la viabilidad del $M$. tuberculosis en esputo no resulta afectada por la adición de fosfato trisódico (FTS) al $10 \%$ en partes iguales, al ser utilizado como decontaminante hasta por 48 horas y mantenido a temperatura ambiente; tampoco disminuyó dicha viabilidad después de sembrar el esputo en medio de Ogawa-Kudoh (O-K) y mantenerlo a temperatura ambiente $\left(20 \pm 2^{\circ} \mathrm{C}\right)$ durante un mes.
\end{abstract}

El método tradicional para cultivar el M. tuberculosis en Colombia es el de Petroff con siembras en medio de Lowenstein-Jensen (L-J). En 1974, Kudoh y Kudoh (1) informaron que al impregnar un escobillón en el esputo e introducirlo durante dos minutos en una solución de $\mathrm{NaOH}$ al $4 \%$ en agua y luego sembrarlo en un medio de Ogawa modificado por Kudoh $(\mathrm{O}-\mathrm{K})$, se obtenían los mismos resultados que con la combinación Petroff-L-J. Sin embargo, estos mismos autores en su trabajo, explicaron por qué el método propuesto por ellos ofrecía mayores ventajas frente al de Petroff-L-J, aunque los resultados fueran similares, y esto se basaba principalmente en que:

1. El medio (Ogawa u Ogawa modificado) que se requiere es comparativamente más fácil de preparar y más económico, ya que no contiene asparagina que es un compuesto costoso y que no se encuentra fácilmente disponible en muchos países.

2. Los procedimientos de inoculación son simples porque no se necesitan equipos especiales y la capacidad amortiguadora del medio, hace que sea posible la inoculación del esputo tratado sin hacer ajustes en el pH.

3. El nuevo método produce menor contaminación de los cultivos aún bajo condiciones desfavorables como la falta de buen entrenamiento de los técnicos que hacen las siembras o que los laboratorios estén equipados inadecuadamente (Tabla 1). Estos datos han sido corroborados por nosotros (2).

Krasnow y Wayne (3) informaron que la viabilidad del $M$. tuberculosis en presencia del fosfato trisódico al 23\% durante 4 horas, no se alteraba en forma significativa. Orozco y col. (4) encontraron que al homogenizar los esputos con FTS al $10 \%$ antes de realizar el procedimiento de Kudoh, se aumentaba la positividad del cultivo y disminuía la contaminación.

Orozco y col. (5) demostraron que no disminuía la viabilidad del $M$. tuberculosis en esputos tratados por 24 horas con FTS al $10 \%$ e incubados inmediatamente después de la siembra según el procedimiento de Kudoh.

\footnotetext{
* Médico Rural. Programa de Enfermedades Infecciosas y Parasitarias, Instituto Nacional de Salud.

** Médico Jefe, Grupo de Micobacterias, Instituto Nacional de Salud.
} 
Basados en los datos anteriores, se realizó el siguiente trabajo para investigar si:

1. La exposición del M. tuberculosis en esputo al FTS al $10 \%$ durante 48 horas disminuía o no su viabilidad.

2. Se disminuía su viabilidad después de sembrar el esputo en O-K, manteniendo los tubos a temperatura ambiente durante un mes.

\section{MATERIALES Y METODOS}

Se utilizó cepa fresca de $M$. tuberculosis H37Rv, cultivado en medio de LowensteinJensen. Luego, se hizo una mezcla de esputos esterilizados en autoclave a $121^{\circ} \mathrm{C}$ por 30 minutos, más FTS al $10 \%$ en partes iguales.

La fórmula para el medio de O-K usado en este estudio de acuerdo a la tabla 1 es como sigue:

Fosfato monopotásico:

2 , gr

Citrato de magnesio:

$0,1 \mathrm{gr}$

Glutamato de sodio:

$0,5 \mathrm{gr}$

Glicerol:

$4,1 \mathrm{ml}$

Agua destilada:

Huevo homogenizado: $100, \mathrm{ml}$

Verde de malaquita $(2 \%)$ :

200, $\mathrm{ml}$

$4, \mathrm{ml}$

TABLA No, 1

COMPARACION ENTRE LOS COMPONENTES DE LOS TRES MEDIOS DE CULTIVO PARA EL II. TUBERCULDSIS (1)

\begin{tabular}{|c|c|c|c|c|c|c|c|}
\hline COMPONENTES & \multicolumn{2}{|l|}{$L-1$} & \multicolumn{2}{|c|}{ OGAWA } & \multicolumn{3}{|c|}{$\begin{array}{l}\text { OGAVA } \\
\text { MODIFICADO }(0-K)\end{array}$} \\
\hline Fosfato monopotásico & $0,4 \mathrm{~g}$ & & 3 & 3 & 2 & g & \\
\hline Sulfato de magnesio & $0,04 \mathrm{~g}$ & & - & & - & & \\
\hline Eitrato de magnesio & $0,1 \mathrm{~g}$ & & - & & 0,1 & 19 & * \\
\hline Glutamato de sodio & - & & 1 & 9 & & 9 & \\
\hline Asparagina & $0,6 \mathrm{~g}$ & & - & & - & & \\
\hline Slicerol & $2 \quad \mathrm{ml}$ & m1 & 6 & $\mathrm{ml}$ & 4 & $\mathrm{~m} 1$ & \\
\hline Agua destilada & 100 & $\mathrm{~m} 1$ & 100 & $\mathrm{m1}$ & 100 & $\mathrm{ml}$ & \\
\hline Huevo homogenizado & 167 & $\mathrm{ml}$ & 200 & $\mathrm{ml}$ & 200 & $\mathrm{~m} 1$ & \\
\hline Verde de malaquita $(2 \%)$ & $3,3 \mathrm{~m}$ & $\mathrm{~m} 1$ & 6 & $\mathrm{ml}$ & 4 & $\mathrm{~m} 1$ & \\
\hline
\end{tabular}

* Este componente no es esencial para la detecciön del bacilo tuberculoso, pera mejora la viabilidad del microorganismo.
Para la siembra de los tubos se procedió de la siguiente manera:

1. Se suspendió M. tuberculosis $\mathrm{H} 37 \mathrm{Rv}$ obtenido de L-J para lograr una concentración de $1 \mathrm{mg} / \mathrm{ml}$ de bacilos en esputo más FTS al 10\% en partes iguales con base en la técnica usual de nefelometría (método de análisis químico y bacteriológico, que consiste en apreciar el brillo de la luz reflejada por las partículas en suspensión en un tubo, comparándola con una suspensión tipo).

2. Se hicieron diluciones progresivas $1 / 10 \mathrm{de}$ la preparación 1 hasta una concentración de $10-4 / \mathrm{mg} / \mathrm{ml}$ de bacilos en esputo más FTS al $10 \%$ en partes iguales.

3. A partir de la dilución 10-4/se hicieron siembras en 24 tubos de O-K con 0,2 ml de la suspensión. Esta suspensión se mantuvo a temperatura ambiente $\left(20-2^{\circ} \mathrm{C}\right)$ antes de realizar las diferentes siembras que se hicieron a las 0,24 y 48 horas, en 8 tubos para cada uno de los tiempos; 4 se incubaron a $37^{\circ} \mathrm{C}$ (Grupo 1) y 4 se dejaron a temperatura ambiente $\left(20-2{ }^{\circ} \mathrm{C}\right.$ ), (Grupo 2) (Esquema No. 1).

Los cultivos mantenidos a temperatura ambiente $\left(20-2{ }^{\circ} \mathrm{C}\right)$ durante 4 semanas (Grupo 2), fueron incubados posteriormente a $37^{\circ} \mathrm{C}$ por un tiempo de 30 días.

4. Los cultivos fueron leídos semanalmente hasta la cuarta semana e interpretados según el Manual de Tuberculosis para América Latina (6). (Tabla 2).

\section{RESULTADOS}

Las siembras del grupo 1 mostraron crecimiento durante un período de cuatro semanas, observándose para las tres primeras semanas de incubación colonias separadas que superaban el número de cien. Al final de la cuarta semana los cultivos presentaban colonias que se hicieron confluentes, las cuales, de acuerdo con el Manual de Tuberculosis para América Latina, corresponde a tres cruces (+*+) para su interpretación. 
EDUARDO ESPER C.. LUIS CARLOS OROZCO V.

ESQUEMA № I

Preparación de las Siembras para el Grupo 1 y 2 ."

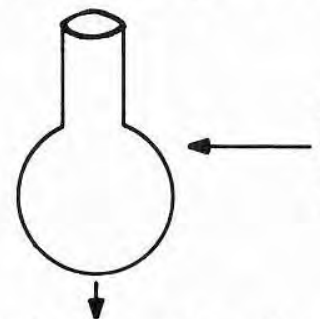

Suspensión de $M$. tuberculosis

$10^{-4} \mathrm{mg} / \mathrm{ml}$ en Esputo + FTS

$10 \%$ I/I Vol.

Siembra de $0,2 \mathrm{ml}$ en medio de $\mathrm{O}-\mathrm{K}$ a las :

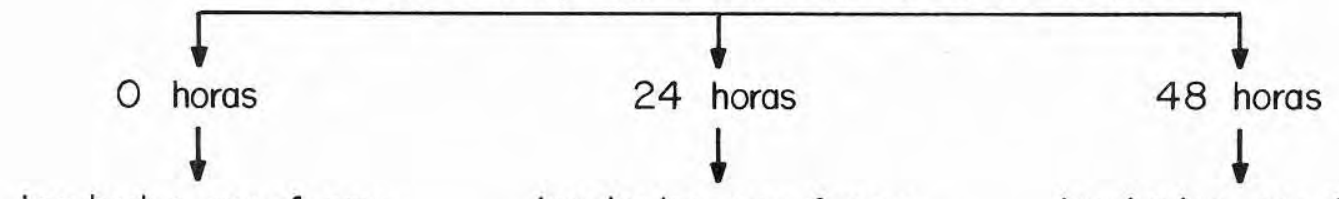

Incubados por 4 sem. Incubados por 4 sem. Incubados por 4 sem.

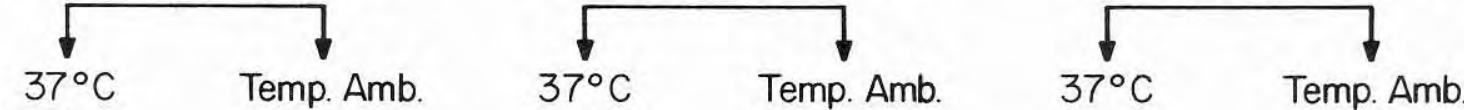

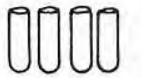

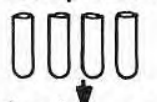

Incubados a $37^{\circ} \mathrm{C}$

por 30 dias
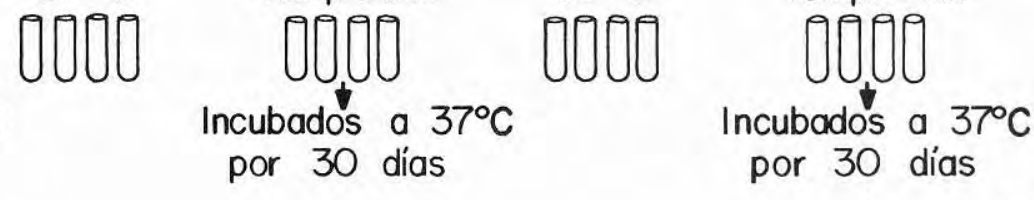

aat

TABLA No. 2

Comparativo entre Grupo 1 y 2

Tiempo

GRUPO $1\left(37^{\circ} \mathrm{C}\right)$

GRUPO $2\left(20 \pm 2^{\circ} \mathrm{C}\right)$

GRUPO $2\left(37^{\circ} \mathrm{C}\right)$ *
A $1 a 3 a$.
A $1 a$ 4a.
A 1a $3 a$.
A 1a $4 a$.
A la $7 a$.
A 1a $8 a$.
semana
semana
semana
semana
semana

0 horas

24 horas

$\begin{array}{ll}++ & +++ \\ ++ & +++ \\ ++ & +++\end{array}$

* Luego de haber sido mantenidas las siembras del Grupo 2 a temperatura ambiente, se procedieron a incubar a $37^{\circ} \mathrm{C}$ por 30 días más. 
Los 12 tubos del grupo 2, que fueron mantenidos a temperatura ambiente (20 $2{ }^{\circ} \mathrm{C}$ ) por cuatro semanas, no mostraron crecimiento. Al finalizar este período, este mismo grupo fue incubado a $37^{\circ} \mathrm{C}$ por 30 días más, presentándose crecimiento en los primeros 20 días con formación de un número de colonias entre 20 y 100 o sea, de (+) a (++), según el Manual de Tuberculosis. Al finalizar la cuarta semana las colonias se hicieron confluentes, o sea que alcanzaron tres cruces ( +++ ), resultado similar al obtenido con el grupo 1.

\section{DISCUSION}

De acuerdo con lo observado en nuestro trabajo, la viabilidad del $M$. tuberculosis no resultó afectada por el FTS al 10\% mezclado en partes iguales con el esputo, después de 48 horas de exposición a temperatura ambiente.

Además, los resultados obtenidos demuestran que la viabilidad del $M$. tuberculosis, no se afecta al conservarse a temperatura ambiente $\left(20-2^{\circ} \mathrm{C}\right)$ durante un mes la siembra de la mezcla esputo-FTS al $10 \%$ (Vol 1:1). Esto abre la posibilidad de hacer siembras de esputo en medio de O-K con previa decontaminación con el FTS al $10 \%$ en partes iguales desde sitios muy distantes con el fin de que estos cultivos puedan ser enviados a incubarse en los laboratorios de referencia.

En el trabajo realizado por kudoh/y Kudoh (1) se observó un aumento de contaminación en esputos que fueron dejados a temperatura ambiente después de sembrados, al ser comparados con los tubos que se incuban a $37^{\circ} \mathrm{C}$ inmediatamente, fenómeno corroborado por Orozco y col. (5) quienes además demostraron que la exposición del esputo al fosfato trisódico disminuía dicha contaminación.

\section{SUMMARY}

A study was done where the viability of the $M$. tuberculosis in sputum was not affected by the addition of ten per cent of trisodium phosphate (TSP) at $10 \%$ in equal parts, when it is used as a decontaminating agent, maintained at room temperature for 48 hours. Nor was its viability altered when it was grown in ogawa/Kudoh (O-K) medium, after having been kept for up to a month at room temperature $\left(20 \pm 2{ }^{\circ} \mathrm{C}\right)$.

\section{AGRADECIMIENTOS}

Se agradece en general al personal del Grupo de Micobacterias del Instituto Nacional de Salud que colaboraron con la realización del trabajo y en especial a las bacteriólogas Otilia Quintero de Ramos, Esneda Giraldo de Blanco, Isabel Ulloa de Moreno y Clara Inés León.

\section{BIBLIOGRAFIA}

1. Kudoh S, Kudoh $\mathrm{T}$., A simple technique for culturing tubercle bacilli. Bull Wld Hlth Org. 1974, 51: 71 .

2. Orozco L.C., León C I., Quintero O., Sarria N. de., Uribe C.M., Ramírez E., Trujillo C., Jaimes E., Martinez F. Una experiencia con un método nuevo para el cultivo de micobacterias. Memorias de la Primera Conferencia Nacional de Tuberculosis y Neumología Roberto Koch, Bogotá, Col., 1982. En prensa.

3. Krasnow I., Wayne L.G. Sputum Digestion. The Mortality Rate of Tubercle Bacilli in Various Digestion Systems. Am. J. Clin. Path. 1966, 45: 352.

4. Orozco L.C., León C.I., Quintero O., Cruz Z., Silva E., López I., Carvajal N., Ramírez T. de. Una modificación al método de Ogawa Kudoh. Memorias de la Primera Conferencia Nacional de Tuberculosis y Neumología Roberto Koch, Bogotá, Col. 1982. En prensa.

5. Orozco L.C., León C.I., Blanco E. de., Moreno I de., Quintero O. Contaminación de esputos expuestos a diferentes concentraciones de Fosfato Trisódico. Observaciones no publicadas.

6. Manual de Bacteriología de la Tuberculosis, Técnicas y Procedimientos Básicos. Organización Mundial de la Salud, Oficina Sanitaria Panamericana. Instituto Nacional para Programas Especiales de Salud. Laboratorio Nacional de Salud "Samper Martinez" Grupo de Tuberculosis. República de Colombia, Ministerio de Salud Pública, 1973, p: 99. 